\title{
In-depth analysis of internal control genes for quantitative real-time PCR in Brassica oleracea var. botrytis
}

\author{
X.G. Sheng ${ }^{1}$, Z.Q. Zhao ${ }^{1}$, H.F. Yu ${ }^{1}$, J.S. Wang ${ }^{1}$, C.F. Zheng ${ }^{2}$ and H.H. Gu ${ }^{1}$ \\ ${ }^{1}$ Institute of Vegetables, Zhejiang Academy of Agricultural Sciences, \\ Hangzhou, China \\ ${ }^{2}$ Zhejiang Mariculture Research Institute, Wenzhou, China \\ Corresponding author: H.H. Gu \\ E-mail: guhh@mail.zaas.ac.cn \\ Genet. Mol. Res. 15 (3): gmr.15038348 \\ Received December 28, 2015 \\ Accepted March 11, 2016 \\ Published July 15, 2016 \\ DOI http://dx.doi.org/10.4238/gmr.15038348
}

Copyright (C) 2016 The Authors. This is an open-access article distributed under the terms of the Creative Commons Attribution ShareAlike (CC BY-SA) 4.0 License.

\begin{abstract}
Quantitative reverse-transcription PCR (qRT-PCR) is a versatile technique for the analysis of gene expression. The selection of stable reference genes is essential for the application of this technique. Cauliflower (Brassica oleracea L. var. botrytis) is a commonly consumed vegetable that is rich in vitamin, calcium, and iron. Thus far, to our knowledge, there have been no reports on the validation of suitable reference genes for the data normalization of qRT-PCR in cauliflower. In the present study, we analyzed 12 candidate housekeeping genes in cauliflower subjected to different abiotic stresses, hormone treatment conditions, and accessions. geNorm and NormFinder algorithms were used to assess the expression stability of these genes. ACT2 and TIP41 were selected as suitable reference genes across all experimental samples in this study. When different accessions were compared, $A C T 2$ and $U N K 3$ were found to be the most
\end{abstract}


suitable reference genes. In the hormone and abiotic stress treatments, $A C T 2, T I P 41$, and UNK2 were the most stably expressed. Our study also provided guidelines for selecting the best reference genes under various experimental conditions.

Key words: Cauliflower; Reference genes; geNorm; NormFinder

\section{INTRODUCTION}

Quantitative real-time PCR (qRT-PCR) is considered a versatile technique for the rapid and reliable quantification of gene transcript levels. Because of its specificity, sensitivity, and capacity for high throughput, qRT-PCR offers a broad range of advantages over standard methods like semi-quantitative PCR and northern blot analysis. Therefore, it is the most reliable method for the absolute and relative quantification of gene transcription levels (Gachon et al., 2004). To accurately quantify gene expression, many variables must be considered, including the quality and quantity of the initial sample, primer design, RNA quality, and amplification efficiencies (Mahoney et al., 2004). A suitable normalization technique is essential for obtaining biological reliable data. Among the many approaches proposed thus far, the selection of appropriate reference genes has been the most frequently used method of normalizing gene expression and reducing potential experimental errors generated in the process of qRT-PCR analysis (Guénin et al., 2009).

Generally, a suitable reference gene should be stably expressed constitutively across treatments, tissues, and developmental stages. A number of endogenous housekeeping genes, such as tubulin $(T U B)$, actin $(A C T)$, glyceraldehyde-3-phosphate dehydrogenase (GAPDH), $18 \mathrm{~S}$ ribosomal RNA (18S $r R N A)$, ubiquitin $(U B Q)$, and elongation factor 1- $\alpha(E F 1-\alpha)$, have been widely used to normalize gene expression data (Nicot et al., 2005). In many cases, these reference genes were used without proper validation, on the supposition that they are constantly expressed because of their role in basic biological processes. However, this concept is misleading since the expression of these genes has been reported to be mutative under different experimental conditions (Tricarico et al., 2002; Gutierrez et al., 2008). Therefore, the systematic validation of appropriate reference genes is a critical step in qRT-PCR analysis to ensure the reliability of experimental data.

In recent years, an increasing number of reports have focused on the systematic validation of reference genes for plants, such as Arabidopsis thaliana (Czechowski et al., 2005; Remans et al., 2008; Hong et al., 2010; Dekkers et al., 2012), wheat (Paolacci et al., 2009; Hua et al., 2014), rice (Jain et al., 2006; Li et al., 2010; Bevitori et al., 2014), lentil (Saha and Vandemark 2013), soybean (Jian et al., 2008; Libault et al., 2008; Hu et al., 2009; Kulcheski et al., 2010; Le et al., 2012; Nakayama et al., 2014), tomato (Dekkers et al., 2012), potato (Nicot et al., 2005; Castro-Quezada et al., 2013), berry (Reid et al., 2006), peach (Tong et al., 2009), coffee (Barsalobres-Cavallari et al., 2009), and tobacco (Schmidt and Delaney, 2010). However, there have been few reports on the selection and validation of suitable reference genes for qRT-PCR analysis in Brassica crops (Qi et al., 2010; Chen et al., 2010; Chandna et al., 2012; Xu et al., 2014).

Cauliflower (Brassica oleracea L. var. botrytis) is an important vegetable crop in the genus Brassica. The whole genome of B. oleracea was recently sequenced, and there is increasing interest in the functional genomics of cauliflower (Wang et al., 2012). In the present

Genetics and Molecular Research 15 (3): gmr.15038348 
study, we aimed to assess the most suitable reference gene(s) for qRT-PCR gene expression studies in Brassica oleracea L. var. botrytis. Based on sequence homology, B. oleracea orthologs of the best $12 \mathrm{~A}$. thaliana housekeeping genes were identified. We compared the performance of these 12 housekeeping genes across a large number of biological samples, using various tissue types, abiotic stress treatments, and accessions of cauliflower. The geNorm (Garson et al., 2005) and Normfinder (Andersen et al., 2004) software programs were used for statistical analysis.

\section{MATERIAL AND METHODS}

\section{Plant material}

A doubled haploid of cauliflower $\left(\mathrm{DH}_{3-2}\right)$ was used for all experiments. Seeds of $\mathrm{DH}_{3-2}$ were germinated and grown in chambers under long-day conditions (14-h light/8-h dark) at a temperature of $24^{\circ}-26^{\circ} \mathrm{C}$. The relative humidity in growth chambers was kept at $60-70 \%$.

\section{Abiotic stress treatments}

For the drought and salt stress treatments, seedlings at the third-true leaf (TTL) stage were transplanted into pots containing $33 \mu \mathrm{M}$ PEG-6000 and $300 \mathrm{mM} \mathrm{NaCl}$, respectively, for 4 and $8 \mathrm{~h}$.

For the heat and cold stress treatments, the seedlings at the TTL stage were kept at $4^{\circ} \pm$ $1^{\circ} \mathrm{C}$ and $39^{\circ} \pm 1^{\circ} \mathrm{C}$, respectively, for 4 and $8 \mathrm{~h}$. After the specified treatment duration, the roots, stems, and leaves were harvested for RNA extraction.

\section{Hormone treatments}

Seedlings at the TTL stage were sprayed with solutions of jasmonic acid $(100 \mu \mathrm{M})$ and gibberellic acid $(100 \mu \mathrm{M})$. Root, stem, and leaf tissues were harvested 4 and $8 \mathrm{~h}$ after the hormone spray.

\section{Different accessions}

Leaves were harvested from six DH lines of cauliflower at the TTL stage, including $\mathrm{DH}_{3-2}, \mathrm{DH}_{3-1}, \mathrm{DH}_{3-6}, \mathrm{DH}_{3-4}, \mathrm{DH}_{3-9}$, and $\mathrm{DH}_{3-14}$. All samples were promptly frozen in liquid nitrogen and then stored in an ultra-low temperature freezer at $-70^{\circ} \mathrm{C}$ until required.

\section{Total RNA extraction and cDNA synthesis}

Total RNA of the samples was extracted using an RNA Simple Total RNA Kit (TaKaRa, Japan) with DNase I (TaKaRa) to eliminate residual genomic DNA, according to the manufacturer protocol. The concentration and purity of the extracted RNA were tested using a NanoPhotometer Spectrophotometer (Germany). Only the RNA samples with an $\mathrm{A}_{260} / \mathrm{A}_{280}$ ratio of 1.8-2.0 and an $\mathrm{A}_{260} / \mathrm{A}_{230}$ ratio higher than 2.0 were selected for subsequent analysis. The integrity of the total RNA was evaluated with electrophoresis by $1.2 \%$ agarose gel.

Genetics and Molecular Research 15 (3): gmr.15038348 
The isolated mRNA (100 ng) was reverse-transcribed to synthesize the first-strand cDNA with an SYBR PrimeScript RT-PCR Kit II (TaKaRa). A total of 100 ng RNA was mixed with the primers, incubated at $65^{\circ} \mathrm{C}$ for $5 \mathrm{~min}$, and then briefly chilled on ice. Next, a transcription mixture was added for reverse transcriptase reaction at $42^{\circ} \mathrm{C}$ lasting $1 \mathrm{~h}$, and first-strand cDNA was synthesized. Finally, the mixture was incubated at $75^{\circ} \mathrm{C}$ for $10 \mathrm{~min}$ to inactivate the reverse transcriptase. All cDNA samples were diluted 1:20 with PCR-grade water before being used for real-time PCR.

\section{Selection of potential reference genes and primer design}

Recently, many superior reference genes have been validated in Arabidopsis. Using these reference genes as queries, the corresponding orthologs were obtained from the $B$. oleracea genome gateway (http://brassicadb.org/brad/). The 12 candidate housekeeping genes selected are listed in Table 1, corresponding to the Arabidopsis Gene Initiative (AGI) locus, $B$. oleracea homolog locus, primer sequences, and PCR efficiency.

Primer pairs for RT-qPCR amplification were designed by Beacon Designer 2.06 with melting temperatures between $54^{\circ}$ and $58^{\circ} \mathrm{C}$, primer lengths of 18 to $20 \mathrm{bp}, \mathrm{GC}$ content of 40 to $55.56 \%$, and amplicon lengths of 113 to $278 \mathrm{bp}$ (Table S1). For each primer pair, the amplification efficiency was estimated by a standard curve produced by a 10 -fold dilution series of pooled $\operatorname{cDNA}\left(1,10,10^{2}, 10^{3}, 10^{4}\right.$, and $10^{5} \mathrm{x}$ dilutions of each gene in triplicate). The PCR amplification efficiency was evaluated by the following equation: $E=\left[10^{(1 /-S)}-1\right] \times 100 \%$, where $S$ indicates the slope of the standard curve.

\section{RT-qPCR and data analysis}

The real-time PCRs were performed on a 96-well optical plate with an iQ5 machine. About $25 \mathrm{ng}$ template (1:20 diluted cDNA), $1 \mu \mathrm{L}(10 \mathrm{pM})$ each primer and 12.5 $\mu \mathrm{L} 2 \mathrm{X}$ SYBR Green PCR Master Mix were mixed in a final volume of $25 \mu \mathrm{L}$. The qRTPCR amplification program was as follows: $95^{\circ} \mathrm{C}$ for 6 min (denaturation), followed by 35 cycles of amplification for $45 \mathrm{~s}$ at $94^{\circ} \mathrm{C}, 40 \mathrm{~s}$ at $58^{\circ} \mathrm{C}$ and $60 \mathrm{~s}$ at $72^{\circ} \mathrm{C}$. All qRTPCRs were performed in biological and technical triplicate, and water without mRNA was used as a control in each run for each gene. Two algorithms, geNorm (version 3.5) and NormFinder (version 0.953), were used to evaluate the expression levels of the 12 housekeeping genes. Data from the three biological replicates were calculated separately in the two algorithms.

\section{RESULTS}

\section{Identification of primer specificity and PCR amplification efficiency}

Prior to the qRT-PCR experiment, primer specificity was determined by agarose gel electrophoresis. For each primer pair, a single PCR product was amplified at the expected size. The analysis of the melting curve also confirmed the specific amplifications of these 12 primer pairs by the presence of a single peak. Amplification efficiency was evaluated, with values ranging from 96 to $104 \%$ (Table 1).

Genetics and Molecular Research 15 (3): gmr.15038348 
Table 1. Brassica oleracea candidate reference gene descriptions and comparison with Arabidopsis.

\begin{tabular}{|c|c|c|c|c|c|c|}
\hline Gene symbol & Gene name & AGI & B. oleracea orthologs & Primer sequence $\left(5^{\prime}-3^{\prime}\right)$ & Amplicon length (bp) & PCR efficiency $(\%)$ \\
\hline UBQ10 & Polyubiquitin 10 & AT4G05320 & Bol030585 & $\begin{array}{l}\text { CATCCAGAAAGATCAACTC } \\
\text { TGCTGGTCTGGAGGAATAC }\end{array}$ & 171 & 98.1 \\
\hline$\overline{E F-1 \alpha}$ & Elongation factor- $1 \alpha$ & AT5G60390 & Bol001470 & $\begin{array}{l}\text { TGCCAACTTCACATCCCAG } \\
\text { ACCAGCATCACCATTCTTC }\end{array}$ & 190 & 101.2 \\
\hline GAPDH & Glyceraldehyde-3-phosphate dehydrogenase & AT1G13440 & Bol010398 & $\begin{array}{l}\text { AGGAATCTGAGGGCAAGCT } \\
\text { CCATTCGTTGTCATACCAC }\end{array}$ & 164 & 97.7 \\
\hline$\overline{\mathrm{ACT} 2}$ & Actin 2 & AT3G18780 & Bol003004 & $\begin{array}{l}\text { GAATCCACGAGACAACATAT } \\
\text { AGGGAAGCAAGAATGGAAC }\end{array}$ & 229 & 99.1 \\
\hline UBC & Ubiquitin conjugating enzyme & AT5G25760 & Bol022331 & $\begin{array}{l}\text { TTATGAAGGCGGAGTGTTT } \\
\text { TGAACCCTCTCGCATCTC }\end{array}$ & 278 & 103.2 \\
\hline UBC9 & Ubiquitin conjugating enzyme 9 & AT4G27960 & Bol021156 & $\begin{array}{l}\text { TGCCCTCACTATCTCCAAG } \\
\text { TGTTCTTGTCTGTCTTGTAC }\end{array}$ & 113 & 98.5 \\
\hline UNK1 & Hypothetical protein & AT4G33380 & Bol017536 & $\begin{array}{l}\text { TTACACACCACAAAGAGAGT } \\
\text { TACAACACCTGAAACCCATG }\end{array}$ & 275 & 101.6 \\
\hline UNK2 & Hypothetical protein & AT2G32170 & Bol006419 & $\begin{array}{l}\text { AAGGATGGAGGAGTTTGGAT } \\
\text { TTCTCTCTTTCTCAATCTCG }\end{array}$ & 151 & 96.4 \\
\hline TIP41 & TIP41-like family protein & AT4G34270 & Bol013651 & $\begin{array}{l}\text { ATTTGGCTGCTCTTTCACTT } \\
\text { AAATCGTAAGAGGAGAAACC }\end{array}$ & 146 & 104.3 \\
\hline$\overline{P D F 2}$ & Protein phosphatase $2 \mathrm{~A}$ subunit $\mathrm{A} 3$ & AT1G13320 & Bol042758 & $\begin{array}{l}\text { CAACCCTCACTATCTGTAC } \\
\text { ATCGTCTTCTCTACAACCG }\end{array}$ & 240 & 97.4 \\
\hline UNK3 & Hypothetical protein & AT4G26410 & Bol039624 & $\begin{array}{l}\text { ATTGCTTGAGAGGTCGGCT } \\
\text { GCAATCCTCTTCTGTCTC }\end{array}$ & 225 & 99.7 \\
\hline$\overline{\text { PTB }}$ & Polypyrimidine tract-binding protein & AT3G01150 & Bol002171 & $\begin{array}{l}\text { GGCAATAGCGAAAGAAGCAT } \\
\text { ACCTGCGTATTGAGTTTGC }\end{array}$ & 177 & 98.4 \\
\hline
\end{tabular}

AGI $=$ Arabidopsis Gene Initiative locus.

\section{Expression stability of candidate reference genes}

The expression stability of the 12 candidate genes in 42 diverse samples was evaluated by qRT-PCR assay with SYBR Green detection. Threshold cycle $(\mathrm{Ct})$ value was used to determine the expression levels of these genes. Overall, the transcripts of these 12 candidate genes exhibited broad variability. The mean $\mathrm{Ct}$ values ranged from 17 to 32, with most falling between 20 and 25 in all detected samples (Figure 1). Among the 12 candidate reference genes, GAPDH had the highest expression level, with a mean Ct of 21.8, and PTB had the lowest expression level (mean Ct of 28.6). However, $P T B$ showed the least variation in expression, with a coefficient of variation value of $9.07 \%$, while $G A P D H(12.99 \%)$ and $E F-1 \alpha$ $(12.72 \%)$ showed the most variation across all detected samples (Figure 1).


Figure 1. Expression levels of candidate reference genes across experimental samples. Values are given as qRTPCR quantification cycle numbers (Ct values).

Genetics and Molecular Research 15 (3): gmr.15038348 


\section{geNorm analysis}

The geNorm software was used to calculate the expression levels of the 12 candidate reference genes and rank them by expression stability value (M). The $M$ value is the average pairwise variation of a particular gene with all the other control genes, which is inversely related to the level of gene expression. A gene with a higher $M$ value has a less stable expression. The geNorm software also suggested a threshold $\mathrm{M}$ value of 1.5 ; values below this number indicated stable expression.

Figure 2 shows the $\mathrm{M}$ values of all genes as calculated by the geNorm algorithm. Most of the genes had an $\mathrm{M}$ value below 1.5, except PTB and $U N K 3$, which had $\mathrm{M}$ values a little higher than 1.5 for the hormone and heat/cold stress treatments and across all tested sample pools. However, the gene with the most stable expression varied among the sample sets. $G A P D H$ and $A C T 2$ showed the most stable expression levels under heat/cold and hormone stress treatments. When the 42 samples were pooled, GAPDH and ACT2 remained the two most stably expressed genes. Under salt and drought stress treatments, the expression levels of TIP41 and UNK3 showed the most stability, and PTB the least stability. In response to the different accessions, UNK2 and UNK3 showed the most stable expression levels and UNK1 the least stable level. Overall, the expression levels of these 12 candidate reference genes exhibited a large variation among the different sample sets. Therefore, it appears necessary to choose one or more suitable reference gene(s) to normalize gene expression for obtaining reliable biological data.

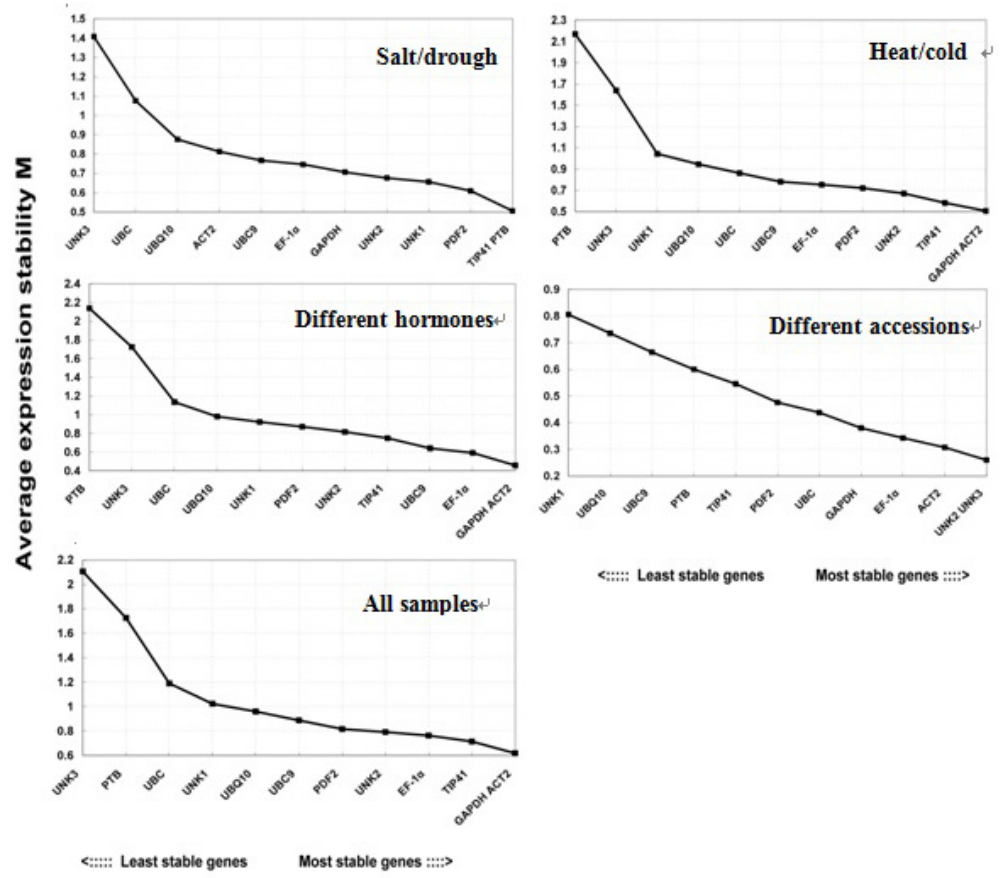

Figure 2. Gene expression stability and ranking of 12 reference genes as calculated by geNorm. Average expression stability (M) following stepwise exclusion of the least stable gene across all the samples within an experimental set. The least stable genes are on the left, and the most stable on the right.

Genetics and Molecular Research 15 (3): gmr.15038348 
The pairwise variation value was also calculated by the geNorm algorithm. This value was used to determine the optimal combination of reference genes for reliable normalization. The threshold of this value was usually set at 0.15 , below which the addition of other reference genes was unnecessary. The results of pairwise variation for each sample set are shown in Figure 3.

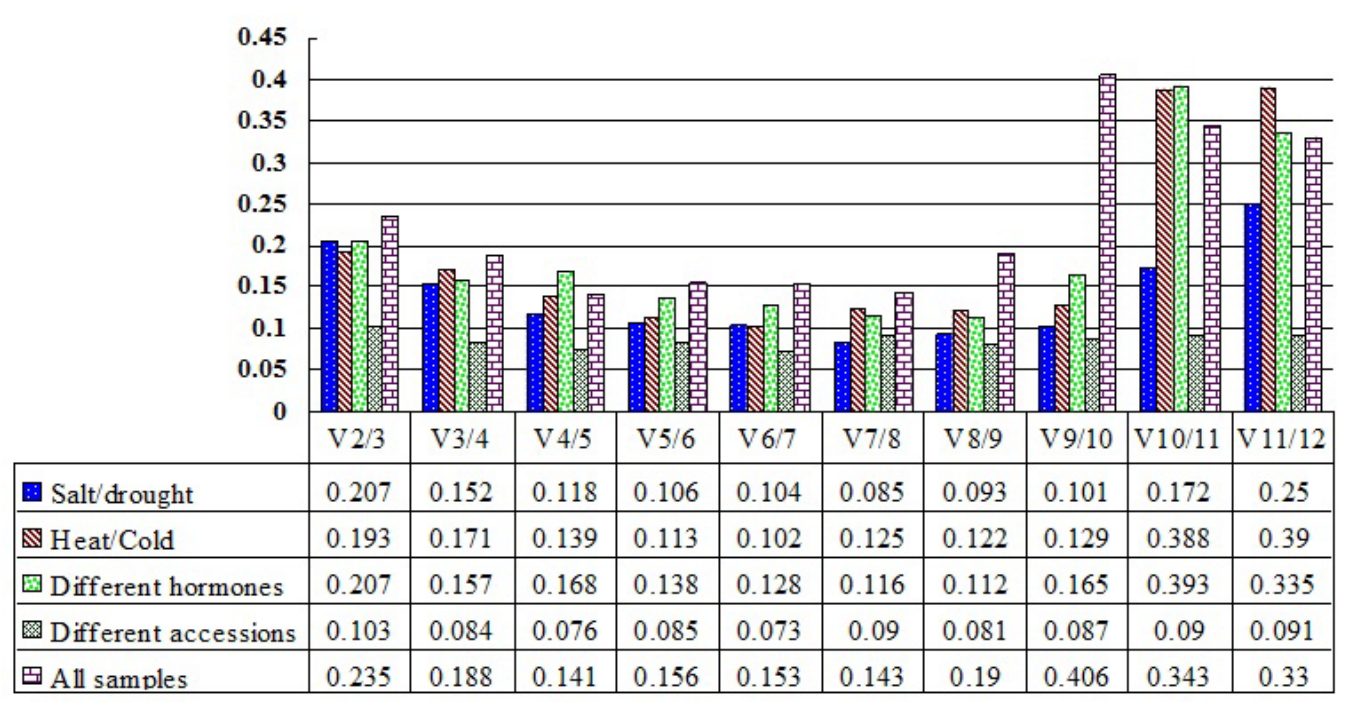

Figure 3. Determination of the optimal number of reference genes for effective normalization. The pairwise variation $(\mathrm{Vn} / \mathrm{Vn}+1)$ between normalization factors $\mathrm{NFn}$ and $\mathrm{NFn}+1$ was analyzed by geNorm to determine the optimal number of reference genes.

Among the series of samples tested, the expression stability levels of these 12 reference genes showed the smallest differences between samples from different accessions (Figure 3). The V2/3 value for different accessions was 0.103 , so UNK2 together with $U N K 3$ would be sufficient for the purpose of normalization. In the salt and drought stress comparison, the V4/5 value was 0.118 , indicating that four reference genes (TIP41, PTB, PDF2, and UNK1) would be needed. However, analysis of the pooled samples and heat/cold treatment showed the suitable reference genes to be GAPDH, ACT2, TIP41, and $U N K 1(\mathrm{~V} 4 / 5$ value $=0.139)$ and $G A P D H, A C T 2, T I P 41$, and $E F-1 \alpha(\mathrm{V} 4 / 5$ value $=0.141)$, respectively. Finally, in the evaluation of samples treated with different hormones, five reference genes (GAPDH, ACT2, $T I P 41, E F-1 \alpha$, and $U B C 9$ ) were suggested (V5/6 value $=0.138)$.

\section{NormFinder analysis}

NormFinder is another algorithm for determining the expression stabilities of candidate reference genes. The expression stability value was calculated by this algorithm for each candidate reference gene based on intra- and inter-group comparison. Table 2 shows the results generated by NormFinder analysis, which differed from those of geNorm. According to NormFinder, $U B C$ was the most stably expressed gene under heat/cold treatment, whereas it was ranked eighth by geNorm. Under salt/drought and hormone treatments, UBC9 and 
TIP41 showed the highest level of expression stability, but these two genes ranked eighth and fifth, respectively, in the geNorm analysis. In samples from different accessions, there was little difference between the analyses of NormFinder and geNorm. ACT2, UNK3, and EF-1 $\alpha$ were determined by NormFinder to be the three most stably expressed genes, whereas $E F-1 \alpha$ was ranked fourth by geNorm. In the samples of all experimental conditions, UNK2 showed the most stable expression, while it was ranked fifth by geNorm. These discrepancies in the results obtained using geNorm and NormFinder were expected because the two programs use completely different statistical algorithms.

Table 2. Expression stability of the reference genes as calculated by the NormFinder software.

\begin{tabular}{|c|c|c|c|c|c|c|c|c|c|c|}
\hline \multirow[t]{2}{*}{ Rank } & \multicolumn{2}{|c|}{ Salt/drought } & \multicolumn{2}{|c|}{ Heat/cold } & \multicolumn{2}{|c|}{ Different hormones } & \multicolumn{2}{|c|}{ Different accessions } & \multicolumn{2}{|c|}{ All samples } \\
\hline & Gene & Stability & Gene & Stability & Gene & Stability & Gene & Stability & Gene & Stability \\
\hline 1 & UBC9 & 0.014 & UBC & 0.017 & TIP41 & 0.014 & ACT2 & 0.004 & UNK2 & 0.013 \\
\hline 2 & UNK2 & 0.015 & TIP41 & 0.020 & UNK2 & 0.015 & UNK3 & 0.006 & TIP41 & 0.019 \\
\hline 3 & UNK1 & 0.017 & UNK2 & 0.022 & PDF2 & 0.019 & EF-1a & 0.011 & ACT2 & 0.030 \\
\hline 4 & EF-1 $\alpha$ & 0.018 & ACT2 & 0.024 & ACT2 & 0.019 & GAPDH & 0.011 & UNK1 & 0.031 \\
\hline 5 & PDF2 & 0.019 & UBQ10 & 0.026 & UNK1 & 0.032 & UNK2 & 0.014 & PDF2 & 0.033 \\
\hline 6 & TIP41 & 0.023 & UNK1 & 0.038 & UBC9 & 0.040 & UBC & 0.015 & UBQ10 & 0.044 \\
\hline 7 & $\mathrm{ACT} 2$ & 0.026 & PDF2 & 0.054 & EF-1a & 0.052 & PDF2 & 0.023 & EF-1 $\alpha$ & 0.048 \\
\hline 8 & PTB & 0.027 & UBC9 & 0.055 & UBQ10 & 0.057 & TIP41 & 0.027 & UBC9 & 0.050 \\
\hline 9 & GAPDH & 0.029 & EF-1a & 0.062 & GAPDH & 0.060 & UBC9 & 0.028 & GAPDH & 0.053 \\
\hline 10 & UBQ10 & 0.034 & GAPDH & 0.064 & UBC & 0.071 & PTB & 0.031 & UBC & 0.062 \\
\hline 11 & UBC & 0.069 & UNK3 & 0.152 & UNK3 & 0.153 & UNK1 & 0.042 & PTB & 0.143 \\
\hline 12 & UNK3 & 0.100 & PTB & 0.176 & PTB & 0.157 & UBQ10 & 0.051 & UNK3 & 0.144 \\
\hline 12 & UNK3 & 0.144 & PTB & 0.176 & UNK3 & 0.100 & PTB & 0.157 & UBQ10 & 0.051 \\
\hline
\end{tabular}

In summary, the results obtained by geNorm and Norm-Finder analysis suggested $A C T 2$ and TIP41 as appropriate reference genes across all experimental samples in this study. For different accessions, $A C T 2$ and $U N K 3$ were found to be the most suitable reference genes. Under abiotic stress and hormone treatments, $A C T 2, T I P 41$, and UNK2 were selected for their stable expression levels.

\section{DISCUSSION}

Real-time qPCR is a versatile technique for assessing gene expression with high repeatability and throughput (Gachon et al., 2004; Song et al., 2015). For reliable data collection, accurate normalization of gene expression is critical in samples with one or more suitable reference genes. The optimum reference gene should exhibit invariable expression levels in all samples regardless of treatment or tissue.

However, we found no single gene with an invariable expression level under all experimental conditions. Consequently, expression stability should be validated for multiple reference genes under various experimental conditions before their use in qPCR normalization. Professional statistical algorithms have greatly simplified the process of reference gene validation. geNorm and NormFinder are the most commonly used algorithms. They can calculate the expression stability value of candidate reference genes and also determine the optimal number of reference genes for accurate and reliable normalization (Vandesompele et al., 2002; Andersen et al., 2004). In the present study, the expression stability of 12 candidate reference genes was validated under five experimental conditions using 42 diverse samples of cauliflower. To our knowledge, this is the first comprehensive analysis of validation of stably expressed reference genes for qPCR in cauliflower from different accessions and under

Genetics and Molecular Research 15 (3): gmr.15038348 
different stress treatments.

Our analysis, which was based on the geNorm and NormFinder algorithms, displayed some variation in which reference genes ranked in the top positions. However, both algorithms consistently determined the most unstably expressed gene. For example, in the heat/cold and hormone treatments, ACT2 and GAPDH showed the most stable expression levels in geNorm, but ranked fourth/tenth and fourth/ninth, respectively, in NormFinder. Across the pooled samples, UNK2 exhibited the highest level of expression stability in NormFinder, but ranked fifth in geNorm. These inconsistencies were expected, since the programs use different statistical algorithms.

geNorm selects the two reference genes with the lowest intra-group expression variation and the highest similarity in expression patterns. In NormFinder, the amount of inter- and intra-group variation is used to rank the genes with the most stable expression (Andersen et al., 2004). Thus, it is understandable that the top reference genes ranked by the two programs were different. Discrepancies between geNorm and NormFinder have also been noted in previous studies (Hong et al., 2008; Wan et al., 2010; Huis et al., 2010).

An increasing number of studies have confirmed that a combination of several reference genes is superior to a single gene for reliable and accurate normalization. However, it is time-consuming and expensive to increase the number of reference genes for normalization. Therefore, the optimum number of reference genes used for normalization should be based on the researcher's considerations. Generally, the two most stably expressed reference genes are effective for reliable normalization. However, in this study, four to five reference genes were required in the most of the sample sets when the geNorm threshold of 0.15 was used. Therefore, this threshold may not be a strict cutoff, and the pairwise variation values may be informative for proposals and suggestions (Hong et al., 2008). Moreover, our analysis also indicated that the selection of suitable reference genes should be based on specific experimental conditions. In the present study, five different optimal reference genes were identified for the five cauliflower sample sets analyzed.

In conclusion, this was the first systematic study to identify and validate appropriate reference genes for data normalization in cauliflower under five experimental conditions, including 42 diverse samples. The results of our analysis with geNorm and NormFinder indicated that $A C T 2$ and TIP41 could be considered suitable reference genes across all experimental samples. ACT2 and UNK3 were the most appropriate reference genes when different accessions were compared. In samples treated with hormones and abiotic stress, ACT2, TIP41, and UNK2 exhibited the most stable expression levels. The results obtained in this paper will facilitate the accurate and sensitive normalization of gene expression in $B$. oleracea and other species of Brassica. In the future, we plan to examine multiple cauliflower varieties to see whether there are differences between species in the selection of reference genes, so as to further verify the reliability of the results obtained in this study.

\section{Conflicts of interest}

The authors declare no conflict of interest.

\section{ACKNOWLEDGMENTS}

Research supported by the Natural Science Foundation of China (\#31201629), the Zhejiang Province for Key Agriculture Development Projects (\#2012C12903), the Science and

Genetics and Molecular Research 15 (3): gmr.15038348 
Technology Department of Zhejiang Province, Zhejiang Academy of Agricultural Sciences, and the Zhejiang Provincial Natural Science Foundation (\#LQ13C030002).

\section{REFERENCES}

Andersen CL, Jensen JL and Ørntoft TF (2004). Normalization of real-time quantitative reverse transcription-PCR data: a model-based variance estimation approach to identify genes suited for normalization, applied to bladder and colon cancer data sets. Cancer Res. 64: 5245-5250. http://dx.doi.org/10.1158/0008-5472.CAN-04-0496

Barsalobres-Cavallari CF, Severino FE, Maluf MP and Maia IG (2009). Identification of suitable internal control genes for expression studies in Coffea arabica under different experimental conditions. BMC Mol. Biol. 10: 1. http://dx.doi. org/10.1186/1471-2199-10-1

Bevitori R, Oliveira MB, Grossi-de-Sá MF, Lanna AC, et al. (2014). Selection of optimized candidate reference genes for qRT-PCR normalization in rice (Oryza sativa L.) during Magnaporthe oryzae infection and drought. Genet. Mol. Res. 13: 9795-9805. http://dx.doi.org/10.4238/2014.November.27.7

Castro-Quezada P, Aarrouf J, Claverie M, Favery B, et al. (2013). Identification of reference genes for normalizing RNA expression in potato roots infected with cyst nematodes. Plant Mol. Biol. Report. 31: 936-945. http://dx.doi. org/10.1007/s11105-013-0566-3

Chandna R, Augustine R, Bisht NC (2012). Evaluation of candidate reference genes for gene expression normalization in Brassica juncea using real-time quantitative RT-PCR. PLoS ONE 7e36918. doi:10.1371/journal.pone.0036918.

Chen X, Truksa M, Shah S and Weselake RJ (2010). A survey of quantitative real-time polymerase chain reaction internal reference genes for expression studies in Brassica napus. Anal. Biochem. 405: 138-140. http://dx.doi.org/10.1016/j. ab.2010.05.032

Czechowski T, Stitt M, Altmann T, Udvardi MK, et al. (2005). Genome-wide identification and testing of superior reference genes for transcript normalization in Arabidopsis. Plant Physiol. 139: 5-17. http://dx.doi.org/10.1104/pp.105.063743

Dekkers BJ, Willems L, Bassel GW, van Bolderen-Veldkamp RP, et al. (2012). Identification of reference genes for RTqPCR expression analysis in Arabidopsis and tomato seeds. Plant Cell Physiol. 53: 28-37. http://dx.doi.org/10.1093/ $\mathrm{pcp} / \mathrm{pcr} 113$

Gachon C, Mingam A and Charrier B (2004). Real-time PCR: what relevance to plant studies? J. Exp. Bot. 55: 1445-1454. http://dx.doi.org/10.1093/jxb/erh181

Garson JA, Grant PR, Ayliffe U, Ferns RB, et al. (2005). Real-time PCR quantitation of hepatitis B virus DNA using automated sample preparation and murine cytomegalovirus internal control. J. Virol. Methods 126: 207-213. http:// dx.doi.org/10.1016/j.jviromet.2005.03.001

Guénin S, Mauriat M, Pelloux J, Van Wuytswinkel O, et al. (2009). Normalization of qRT-PCR data: the necessity of adopting a systematic, experimental conditions-specific, validation of references. J. Exp. Bot. 60: 487-493. http:// dx.doi.org/10.1093/jxb/ern305

Gutierrez L, Mauriat M, Guénin S, Pelloux J, et al. (2008). The lack of a systematic validation of reference genes: a serious pitfall undervalued in reverse transcription-polymerase chain reaction (RT-PCR) analysis in plants. Plant Biotechnol. J. 6: 609-618. http://dx.doi.org/10.1111/j.1467-7652.2008.00346.x

Hong SM, Bahn SC, Lyu A, Jung HS, et al. (2010). Identification and testing of superior reference genes for a starting pool of transcript normalization in Arabidopsis. Plant Cell Physiol. 51: 1694-1706. http://dx.doi.org/10.1093/pcp/pcq128

Hong SY, Seo PJ, Yang MS, Xiang F, et al. (2008). Exploring valid reference genes for gene expression studies in Brachypodium distachyon by real-time PCR. BMC Plant Biol. 8: 112. http://dx.doi.org/10.1186/1471-2229-8-112

Hu R, Fan C, Li H, Zhang Q, et al. (2009). Evaluation of putative reference genes for gene expression normalization in soybean by quantitative real-time RT-PCR. BMC Mol. Biol. 10: 93. http://dx.doi.org/10.1186/1471-2199-10-93

Hua W, Zhu JH, Shang Y, Wang JM, et al. (2014). Identification of suitable reference genes for barley gene expression under abiotic stresses and hormonal treatments. Plant Mol. Biol. Report. 1: 1-14.

Huis R, Hawkins S and Neutelings G (2010). Selection of reference genes for quantitative gene expression normalization in flax (Linum usitatissimum L.). BMC Plant Biol. 10: 71. http://dx.doi.org/10.1186/1471-2229-10-71

Jain M, Nijhawan A, Tyagi AK and Khurana JP (2006). Validation of housekeeping genes as internal control for studying gene expression in rice by quantitative real-time PCR. Biochem. Biophys. Res. Commun. 345: 646-651. http://dx.doi. org/10.1016/j.bbrc.2006.04.140

Jian B, Liu B, Bi Y, Hou W, et al. (2008). Validation of internal control for gene expression study in soybean by quantitative real-time PCR. BMC Mol. Biol. 9: 59. http://dx.doi.org/10.1186/1471-2199-9-59

Genetics and Molecular Research 15 (3): gmr.15038348 
Kulcheski FR, Marcelino-Guimaraes FC, Nepomuceno AL, Abdelnoor RV, et al. (2010). The use of microRNAs as reference genes for quantitative polymerase chain reaction in soybean. Anal. Biochem. 406: 185-192. http://dx.doi. org/10.1016/j.ab.2010.07.020

Le DT, Aldrich DL, Valliyodan B, Watanabe Y, et al. (2012). Evaluation of candidate reference genes for normalization of quantitative RT-PCR in soybean tissues under various abiotic stress conditions. PLoS ONE 7e46487. doi:10.1371/ journal.pone 0046487.

Li QF, Yuan DY, Yu HX, Gu MH, et al. (2010). Validation of candidate reference genes for the accurate normalization of real-time quantitative RT-PCR data in rice during seed development. Plant Mol. Biol. Report. 28: 49-57. http:// dx.doi.org/10.1007/s11105-009-0124-1

Libault M, Thibivilliers S, Bilgin DD, Radwan O, et al. (2008). Identification of four soybean reference genes for gene expression normalization. Plant Genome 1: 44-54. http://dx.doi.org/10.3835/plantgenome2008.02.0091

Mahoney DJ, Carey K, Fu MH, Snow R, et al. (2004). Real-time RT-PCR analysis of housekeeping genes in human skeletal muscle following acute exercise. Physiol. Genomics 18: 226-231. http://dx.doi.org/10.1152/ physiolgenomics.00067.2004

Nakayama TJ, Rodrigues FA, Neumaier N, Marcelino-Guimarães FC, et al. (2014). Reference genes for quantitative realtime polymerase chain reaction studies in soybean plants under hypoxic conditions. Genet. Mol. Res. 13: 860-871. http://dx.doi.org/10.4238/2014.February.13.4

Nicot N, Hausman JF, Hoffmann L and Evers D (2005). Housekeeping gene selection for real-time RT-PCR normalization in potato during biotic and abiotic stress. J. Exp. Bot. 56: 2907-2914. http://dx.doi.org/10.1093/jxb/eri285

Paolacci AR, Tanzarella OA, Porceddu E and Ciaffi M (2009). Identification and validation of reference genes for quantitative RT-PCR normalization in wheat. BMC Mol. Biol. 10: 11. http://dx.doi.org/10.1186/1471-2199-10-11

Qi JN, Yu SC, Zhang FL, Sheng XQ, et al. (2010). Reference gene selection for real-time quantitative polymerase chain reaction of mRNA transcript levels in Chinese cabbage (Brassica rapa L. ssp. pekinensis). Plant Mol. Biol. Report. 28: 597-604. http://dx.doi.org/10.1007/s11105-010-0185-1

Reid KE, Olsson N, Schlosser J, Peng F, et al. (2006). An optimized grapevine RNA isolation procedure and statistical determination of reference genes for real-time RT-PCR during berry development. BMC Plant Biol. 6: 27. http:// dx.doi.org/10.1186/1471-2229-6-27

Remans T, Smeets K, Opdenakker K, Mathijsen D, et al. (2008). Normalisation of real-time RT-PCR gene expression measurements in Arabidopsis thaliana exposed to increased metal concentrations. Planta 227: 1343-1349. http:// dx.doi.org/10.1007/s00425-008-0706-4

Saha GC and Vandemark GJ (2013). Stability of expression of reference genes among different lentil (Lens culinaris) genotypes subjected to cold stress, white mold disease, and Aphanomyces root rot. Plant Mol. Biol. Report. 31: 11091115. http://dx.doi.org/10.1007/s11105-013-0579-y

Schmidt GW and Delaney SK (2010). Stable internal reference genes for normalization of real-time RT-PCR in tobacco (Nicotiana tabacum) during development and abiotic stress. Mol. Genet. Genomics 283: 233-241. http://dx.doi. org/10.1007/s00438-010-0511-1

Song JH, Yang J, Pan F and Jin B (2015). Differential expression of microRNAs may regulate pollen development in Brassica oleracea. Genet. Mol. Res. 14: 15024-15034. http://dx.doi.org/10.4238/2015.November.24.10

Tong Z, Gao Z, Wang F, Zhou J, et al. (2009). Selection of reliable reference genes for gene expression studies in peach using real-time PCR. BMC Mol. Biol. 10: 71. http://dx.doi.org/10.1186/1471-2199-10-71

Tricarico C, Pinzani P, Bianchi S, Paglierani M, et al. (2002). Quantitative real-time reverse transcription polymerase chain reaction: normalization to rRNA or single housekeeping genes is inappropriate for human tissue biopsies. Anal. Biochem. 309: 293-300. http://dx.doi.org/10.1016/S0003-2697(02)00311-1

Vandesompele J, De Preter K, Pattyn F, Poppe B, et al. (2002). Accurate normalization of real-time quantitative RT-PCR data by geometric averaging of multiple internal control genes. Genome Biol. 3: H0034. http://dx.doi.org/10.1186/ gb-2002-3-7-research0034

Wan H, Zhao Z, Qian C, Sui Y, et al. (2010). Selection of appropriate reference genes for gene expression studies by quantitative real-time polymerase chain reaction in cucumber. Anal. Biochem. 399: 257-261. http://dx.doi. org/10.1016/j.ab.2009.12.008

Wang W, Huang S, Liu Y, Fang Z, et al. (2012). Construction and analysis of a high-density genetic linkage map in cabbage (Brassica oleracea L. var. capitata). BMC Genomics 13: 523. http://dx.doi.org/10.1186/1471-2164-13-523

Xu XY, Yang ZP, Sun XL, Zhang LG, et al. (2014). Selection of reference genes for quantitative real-time PCR during flower bud development in CMS7311 of heading Chinese cabbage (Brassica rapa L. ssp. pekinensis). Acta Physiol. Plant. 36: 809-814. http://dx.doi.org/10.1007/s11738-013-1437-0

Genetics and Molecular Research 15 (3): gmr.15038348 


\section{Supplementary material}

Table S1. Primer description of the 12 candidate reference genes.

Genetics and Molecular Research 15 (3): gmr.15038348 